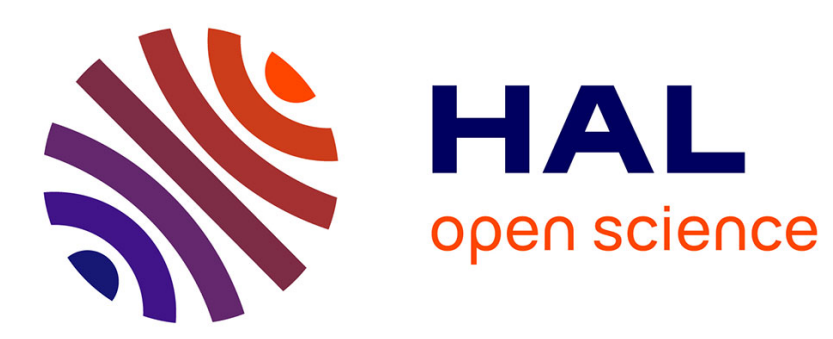

\title{
La nature des exsudats de raisins et leur rôle dans la germination des conidies de Botrytis cinerea
}

Bernard Doneche

\section{To cite this version:}

Bernard Doneche. La nature des exsudats de raisins et leur rôle dans la germination des conidies de Botrytis cinerea. Agronomie, 1986, 6 (1), pp.67-73. hal-00884849

\section{HAL Id: hal-00884849 \\ https://hal.science/hal-00884849}

Submitted on 1 Jan 1986

HAL is a multi-disciplinary open access archive for the deposit and dissemination of scientific research documents, whether they are published or not. The documents may come from teaching and research institutions in France or abroad, or from public or private research centers.
L'archive ouverte pluridisciplinaire HAL, est destinée au dépôt et à la diffusion de documents scientifiques de niveau recherche, publiés ou non, émanant des établissements d'enseignement et de recherche français ou étrangers, des laboratoires publics ou privés. 


\title{
La nature des exsudats de raisins et leur rôle dans la germination des conidies de Botrytis cinerea
}

\author{
Bernard DONECHE \\ Institut d'Oenologie, Université de Bordeaux II, 351, Cours de la Libération, F 33405 Talence
}

RÉSUMÉ

\begin{abstract}
Le lavage de baies de raisins à maturité a montré la présence de substances de faible poids moléculaire à la surface des raisins. Ces substances stimulent la germination des conidies et la croissance mycélienne de Botrytis cinerea. Au cours de la maturation, le rapport sucres/acides des eaux de lavage évolue de façon similaire à la constitution interne du raisin. Mais à maturité, l'augmentation importante des sucres exsudés semble liée à l'altération des parois cellulaires de la pellicule du raisin.
\end{abstract}

Mots clés additionnels : Vitis vinifera, relation hôte-parasite, maturation.

The nature of the exudates of grape berries and their effect on germination of conidia of Botrytis cinerea.

Washing water from the surface of ripe grape berries contained compounds of low molecular weight. These nutrients stimulated germination of conidia and mycelial growth of Botrytis cinerea. During maturation, the sugar/acid ratio of the washing water paralleled that of the grape juice itself. At maturity, the increase of sugars in the washing water appeared to result from an alteration in the cell-wall composition of the berry skin.

Additional key words : Vitis vinifera, host-parasite relationship, maturation.

\section{INTRODUCTION}

Le champignon Botrytis cinerea Pers. est un redoutable parasite ; il infecte indifféremment les feuilles, les fleurs ou les fruits de nombreux végétaux. L'eau est le paramètre principal de cette infection. Il est parfaitement connu que le développement de la pourriture due à $B$. cinerea se produit toujours après une période pluvieuse ou d'épais brouillards.

Mais dès 1922, BROWN montre que des substances stimulant la germination des conidies de $B$. cinerea sont extraites par des gouttes d'eau déposées à la surface des feuilles. Ce phénomène est vérifié par NELSON (1951) au cours de la conservation des raisins de table en chambre humide. L'identité de ces substances a été difficile à établir. DeVERALL \& WOOD (1961), travaillant avec Botrytis fabae, observent qu'une addition de sucres à une suspension de conidies, appliquée à la surface de feuilles de fève, augmente le nombre et la taille des lésions.

En 1964, KosUGE \& HewitT constatent que les eaux de lavage de baies de raisin parvenues à maturité renferment des sucres simples (glucose et fructose) et des acides aminés. Leurs travaux mettent en évidence l'utilisation des sucres comme source d'énergie pour la germination des conidies de $B$. cinerea. Les acides aminés, par contre, ne jouent aucun rôle dans l'infection des baies de raisin par le champignon.

La présente étude confirme l'existence de sucres simples dans les exsudats de raisin ; elle montre également la variation de leur concentration au cours de la maturation des baies et leur influence sur la germination des conidies de $\boldsymbol{B}$. cinerea.

\section{MATÉRIEL ET MÉTHODES}

Les prélèvements de raisins ont été réalisés en septembre et octobre 1984 dans différentes parcelles du vignoble de Bordeaux, France :

- parcelle A : cépage Sémillon (blanc) (Sauternes),

- parcelle B : cépage Sémillon (blanc) (Graves),

- parcelle C : cépage Merlot (noir) (Pomerol),

- parcelle D : cépage Merlot (noir) (Saint-Emilion). 
Les parcelles $A$ et $D$ présentent une prédisposition plus grande au développement de $B$. cinerea que les parcelles B et C.

Les baies de raisin ( 30 à 50 par parcelle) sont collectées par section à mi-longueur du pédicelle. L'observation de chaque baie permet de vérifier son état sanitaire et l'intégrité de sa pellicule.

Les baies sont trempées, individuellement et sous agitation, dans $5 \mathrm{ml}$ d'eau distillée à $30{ }^{\circ} \mathrm{C}$ pendant $2 \mathrm{mn}$. Afin d'éviter toute pollution par un éventuel suintement au niveau de l'attache du pédicelle, seulement les $9 / 10$ inférieurs des baies sont immergés (fig. 1).

Les eaux de lavage de toutes les baies d'un prélèvement sont assemblées et filtrées sur membrane $(0,45 \mu \mathrm{m})$ afin d'éliminer les microorganismes présents à la surface des raisins. L'échantillon est ensuite concentré 20 fois. La détermination des sucres simples (glucose et fructose) est réalisée par méthode enzymatique (BERGMEYER, 1974).

L'acidité est mesurée par variation de la densité optique à $420 \mathrm{~nm}$ d'une solution de pourpre de bromocrésol tamponnée à pH 5,0 par rapport à une solution étalon d'acide tartrique. Les teneurs en composés azotés (nitrate, nitrite, ammonium et acides aminés) sont estimées de façon semi-quantitative avec un réactif spécifique (N-I-naphthyl-éthylènediamine, potassium tétraiodomercurate et ninhydrine).

Les expériences de germination de conidies ont été réalisées avec la souche de $B$. cinerea C.77.4 (Collection de l'Institut d'Oenologie de Bordeaux). Le champignon est cultivé sur extrait de malt gélosé (milieu incliné en tubes) 10 jours à $26^{\circ} \mathrm{C}$. Après développement, les conidies sont mises en suspension par addition de $5 \mathrm{ml}$ d'eau distillée stérile et agitation. La suspension de conidies est passée sur une couche mince de laine de verre pour éliminer les fragments de mycélium. Les conidies sont ensuite retenues sur membrane filtrante de porosité $0,45 \mu \mathrm{m}$, lavées et remises en suspension dans de l'eau distillée stérile.

Les tests de germination sont réalisés par incubation à $20^{\circ} \mathrm{C}$, en milieu saturé en eau, de tubes de $1 \mathrm{ml}$ contenant $0,1 \mathrm{ml}$ de suspension de conidies et $0,1 \mathrm{ml}$ de solution de lavage des baies de raisin ramenée à la concentration initiale (diluée 20 fois). La numération des conidies germées est effectuée au microscope à intervalles de temps réguliers.

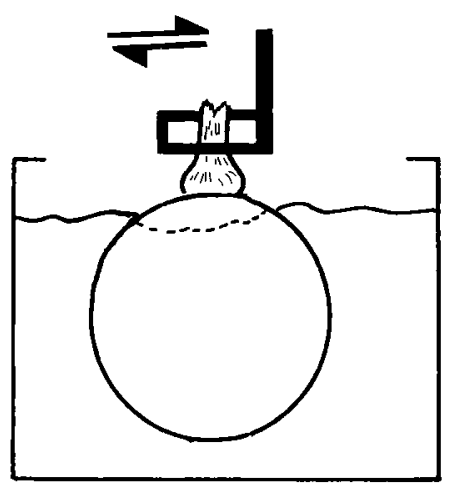

Figure 1

Dispositif de lavage des baies de raisin.

Apparatus for washing grape berries.
La mesure de la vitesse d'élongation du tube germinatif est effectuée à l'aide d'une suspension de conidies lavées selon la technique précédente. Cette suspension de conidies $(0,1 \mathrm{ml})$ est mélangée à $0,5 \mathrm{ml}$ de solution de lavage des baies de raisin (ramenée à la concentration initiale) et mise à incuber à $20^{\circ} \mathrm{C}$. Après germination, les conidies sont recueillies sur membrane filtrante de porosité $0,45 \mu \mathrm{m}$, lavées et remises en suspension avec $0,1 \mathrm{ml}$ de solution de lavage des baies de raisin (ramenée à la concentration initiale), ce qui permet de juger uniquement l'effet sur l'élongation du tube germinatif.

L'incubation est conduite à $20^{\circ} \mathrm{C}$ en milieu humide. La mesure de la longueur des tubes germinatifs est réalisé, à intervalles de temps réguliers, au microscope à l'aide d'un système micrométrique.

Le taux de croissance de $B$. cinerea, par utilisation de substances nutritives contenues dans les eaux de lavage des raisins, est établi par culture du champignon sur $2 \mathrm{ml}$ de solution concentrée de lavage. L'ensemencement est réalisé avec $0,1 \mathrm{ml}$ d'une suspension de conidies. L'incubation en boîtes de Petri (diamètre $=2,5 \mathrm{~cm}$ ) dure $8 \mathrm{j}$ à $25^{\circ} \mathrm{C}$. Après développement du champignon, le mycélium est dilacéré puis additionné de $3 \mathrm{ml}$ de $\mathrm{NaOH} \mathrm{N}$ à $90{ }^{\circ} \mathrm{C}$. Les fragments de mycélium sont éliminés par filtration. Les protéines extraites par $\mathrm{NaOH}$ sont précipitées par l'acide trichloracétique à $20 \mathrm{p} .100(\mathrm{P} / \mathrm{V})$ et recueillies par centrifugation $5 \mathrm{mn}$ à $5000 \mathrm{~g}$. Le précipité protéique est dissous dans $1 \mathrm{ml}$ d'eau distillée. L'opération est renouvelée 2 fois afin d'éliminer les substances susceptibles d'interférer. La concentration en protéines est déterminée par le rapport E 280/E 260 (WARBURG \& CHRISTIAN, 1941).

Les mesures de germination de conidies, de vitesse d'élongation du tube germinatif et du taux de croissance mycélienne sont effectuées avec des suspensions contenant de 1650 à 1850 conidies par ml. Les résultats de ces expériences sont obtenus par comparaison avec un témoin réalisé dans de l'eau distillée stérile et sont la moyenne de 3 déterminations.

Parallèlement, les baies de raisin ayant servi à l'obtention des eaux de lavage sont broyées, le jus est séparé des matières solides et les teneurs en sucres simples (glucose et fructose) et en acides totaux sont déterminées sur ces jus. La comparaison de ces résultats avec ceux obtenus pour des échantillons plus importants ( 2000 baies) sur les mêmes parcelles permet de juger de la représentativité de notre échantillon.

\section{RÉSULTATS}

\section{A. Exsudation de substances nutritives par les baies de raisin}

L'eau de lavage d'une baie de raisin parvenue à maturité renferme diverses substances de poids moléculaire faible (tabl. 1).

La teneur en sucres simples (glucose et fructose) est importante, notamment dans le cas du raisin blanc. Malgré une concentration non négligeable en acides, le $\mathrm{pH}$ est proche de la neutralité, ce qui permet de supposer que les eaux de lavage contiennent différents cations non identifiés. Il faut également noter la pré- 
TABLEAU 1

Composition chimique de l'eau de lavage d'une baie de raisin à maturité.

Chemical composition of washing water of mature grape berries.

\begin{tabular}{|c|c|c|}
\hline Constituants & $\begin{array}{l}\text { Semillon } \\
\text { blanc }\end{array}$ & $\begin{array}{l}\text { Merlot } \\
\text { noir }\end{array}$ \\
\hline Glucose $(\mu \mathrm{M} /$ baie $)$ & 0,871 & 0,068 \\
\hline Fructose $(\mu \mathrm{M} /$ baie $)$ & 0,837 & 0,067 \\
\hline Aminoacides $(\mu \mathrm{M} /$ baie $)$ & $0,025-0,035$ & $0,001-0,002$ \\
\hline Acides totaux ( $\mu$ éq/baie) & 0,138 & 0,038 \\
\hline $\mathrm{NO}_{3}^{-}(\mu$ éq/baie $)$ & $0,01-0,02$ & $0,002-0,005$ \\
\hline $\mathrm{NH}_{4}^{+}$( $\mu$ éq/baie $)$ & traces & traces \\
\hline pH & 6,35 & 6,20 \\
\hline
\end{tabular}

sence d'azote sous formes organique et minérale. Les différences entre les 2 cépages sont nettement supérieures à la différence de volume respectif des baies.

Afin de préciser ce phénomène d'exsudation de molécules simples à travers la pellicule du raisin, le traitement de lavage a été répété sur un lot homogène de baies saines. Après chaque lavage, les baies sont soigneusement essuyées et conservées dans des flacons hermétiques individuels.

Lorsque le lavage est effectué à intervalles de temps réguliers, les quantités de sucres et d'acides extraites sont relativement constantes (fig. 2). Par contre, leurs concentrations croissent lorsque le temps d'incubation entre chaque lavage augmente et surtout lorsqu'il est supérieur à $3 \mathrm{~h}$ (fig. 3 ).

Les conditions d'expérience (conservation après trempage de la baie à l'intérieur d'un flacon hermétique) doivent provoquer une transpiration naturelle. Pour de telles durées d'incubation, les molécules transpirées s'ajoutent aux molécules exsudées extraites par l'eau de lavage.

\section{B. Evolution de la composition des exsudats au cours de la maturation du raisin}

Le lavage a été pratiqué régulièrement au cours de la maturation 1984 sur des échantillons de raisins représentatifs des 4 parcelles étudiées.

$\mathrm{Au}$ cours de la maturation la teneur en sucres des exsudats augmente progressivement tandis que la concentration en acides totaux diminue (fig. 4). Cette évolution est d'importance variable selon les parcelles ; la quantité de sucres exsudés est ainsi quintuplée dans la parcelle A. Inversement, la diminution des acides exsudés est surtout marquée dans le cas de la parcelle $\mathrm{C}$.

De telles variations semblent résulter simplement des modifications de la constitution chimique interne du raisin. Effectivement, si l'on compare l'évolution des teneurs en sucres et en acides des exsudats et des raisins, l'allure générale est identique (fig. 5). Cette similitude est surtout nette en milieu de maturation. En fin de maturation, la quantité de sucres exsudés augmente plus vite que la richesse en sucres du raisin. Si l'on exprime les quantités de sucres exsudés par $\mathrm{cm}^{2}$ de surface, le phénomène est plus accentué car le volume des baies n'augmente que faiblement au voisinage de la maturité. Dans le cas de la parcelle $C$ et lors de la dernière semaine, la teneur en sucres des

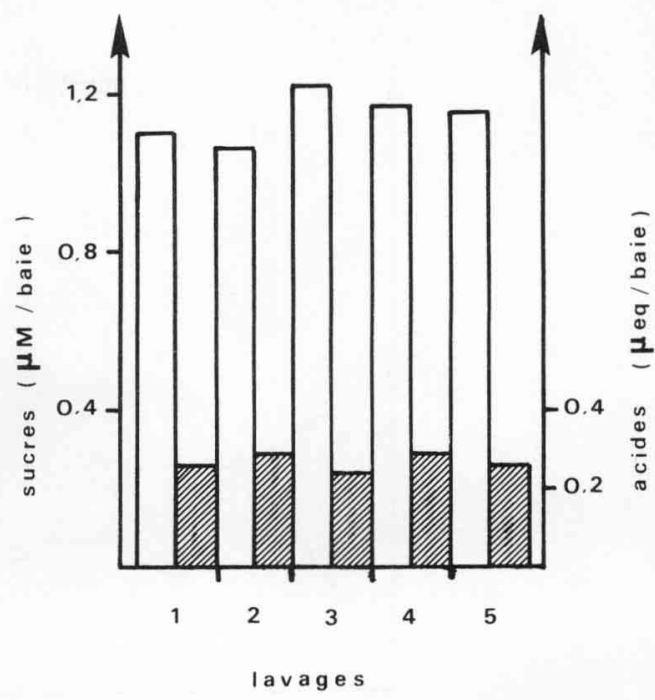

Figure 2

Composition des eaux de lavage lors de traitements répétés à intervalles de temps réguliers $(2 \mathrm{~h})$.

Composition of washing water for repeated treatments at regular periods $(2 \mathrm{~h})$.

$\square$ sucres; (sugars)

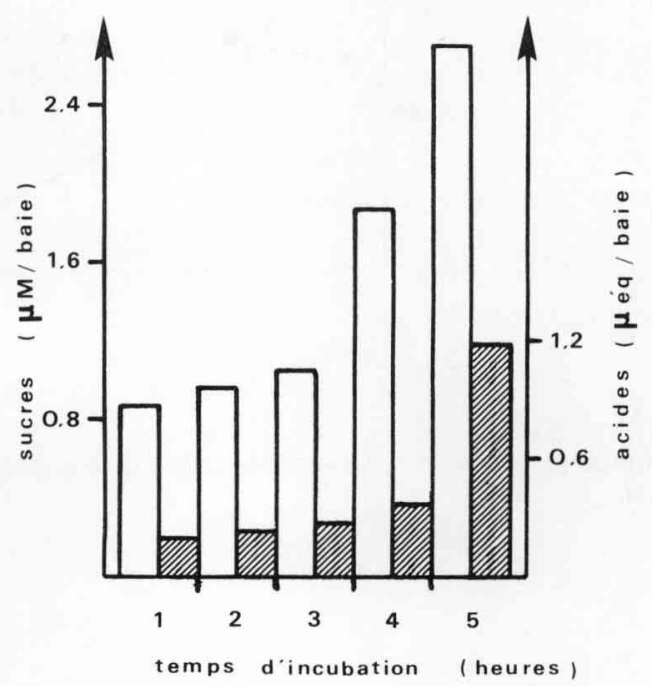

Figure 3

Composition des eaux de lavage lors de traitements répétés à intervalles de temps croissants.

Composition of washing water for repeated treatments at increased periods.

sucres; (

acides; (acids)

exsudats croît de 30 p. 100 alors que les sucres internes restent pratiquement constants (plus 1,5 p. 100 seulement). Ce phénomène est moins marqué dans le cas de la parcelle $A$ où le raisin ne semble pas être parvenu à complète maturité en fin d'expérience ; la teneur en sucres internes augmentant encore de près de 2 p. 100 au cours des 8 derniers jours. Il faut également noter la diminution très rapide de la concentration en acides des exsudats. 

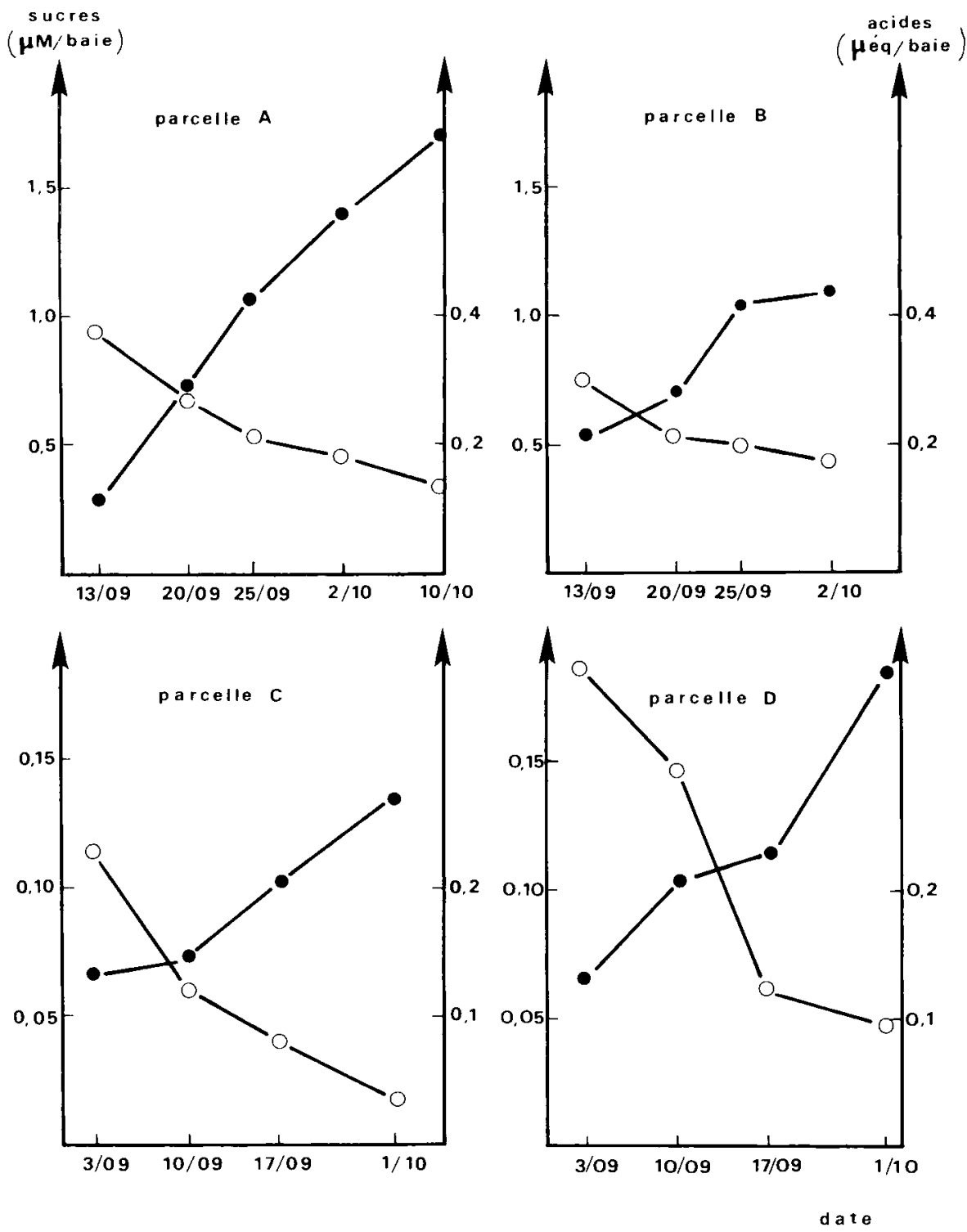

Figure 4

Evolution de la composition des exsudats au cours de la maturation du raisin.

Change in the composition of exudates during grape maturation.

(๑) teneur en sucres ( $\mu M /$ baie); sugar level ( $\mu$ mole/berry).

(O) teneur en acides ( $\mu$ éq/baie); acid level ( $\mu$ eq/berry).

\section{Influence des exsudats de raisin sur le dévelop- pement de $B$. cinerea}

La germination des conidies de $B$. cinerea est accrue en présence des exsudats de raisin (fig. 6). Cette stimulation est particulièrement nette dans le cas des parcelles A et B, certainement en relation avec une plus grande richesse en sucres des exsudats. Il intervient également la différence de nature entre cépage blanc et cépage rouge, ainsi qu'entre les parcelles.

Pour le cépage "Sémillon blanc", les résultats montrent que, pour une même concentration en sucres des exsudats (par exemple $1 \mu \mathrm{M} /$ baie), la germination est plus intense dans le cas de la parcelle A. Il en est de même pour le cépage "Merlot noir » où les exsudats issus de la parcelle $\mathrm{C}$ semblent les plus favorables à la germination des conidies pour une concentration de $0,1 \mu \mathrm{M}$ de sucres/baie. Cette différence se retrouve au niveau de la vitesse d'élongation du tube germinatif (tabl. 2).

Mais pour chaque cépage, il faut noter que le développement mycélien (représenté par la teneur en protéines après culture sur les exsudats) n'est pas directement en relation avec la teneur en sucres des exsudats. Cette détermination du taux de croissance ne semble pas être une mesure fiable de l'influence des exsudats. En effet, le développement de $B$. cinerea sur les exsudats issus des parcelles $\mathrm{B}, \mathrm{C}, \mathrm{D}$, conduit à un feutrage mycélien dense avec une faible émission de conidiophores, tandis que, dans le cas de la parcelle A, le champignon forme de longs filaments dont les ramifications portent de nombreux conidiophores. Ces 2 types de développement conduisent vraisemblablement à des teneurs différentes en protéines. 

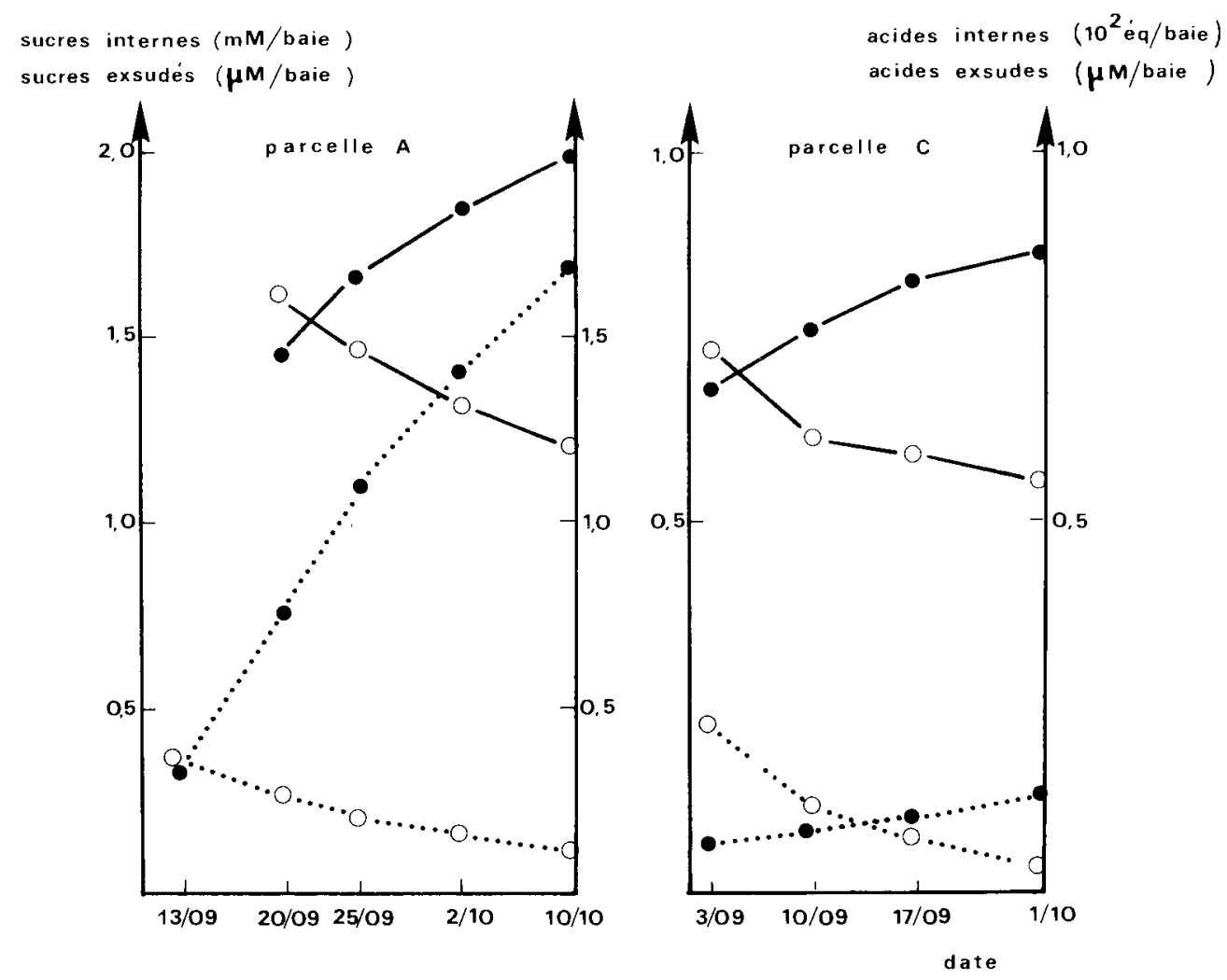

Figure 5

Relation entre la constitution interne et la composition des exsudats au cours de la maturation du raisin.

Relationship between internal constitution and composition of exudates during grape maturation.

(๑......) teneur en sucres des exsudats ( $\mu M /$ baie) ; sugar level of exudates ( $\mu$ mole/berry).

TABLEAU 2

Influence des exsudats de raisins sur le développement de Botrytis cinerea.

Effect of grape berry exudates on the growth of Botrytis cinerea.

\begin{tabular}{crrrc}
\hline \hline \multirow{2}{*}{ Prélèvements } & $\begin{array}{c}\text { Vitesse d'élongation } \\
\text { du tube germinatif } \\
(\mu \mathrm{m} \text { après } 4 \mathrm{~h})\end{array}$ & \multicolumn{2}{c}{$\begin{array}{c}\text { Taux de protéines } \\
(\mu \mathrm{g} / \text { exsudat } 1 \text { baie } \\
\text { après } 7 \mathrm{j} \text { culture) }\end{array}$} \\
\hline & \multicolumn{2}{c}{ Parcelles } & \multicolumn{2}{c}{ Parcelles } \\
\cline { 2 - 5 } & $\mathrm{A}$ & $\mathrm{B}$ & $\mathrm{A}$ & $\mathrm{B}$ \\
\cline { 2 - 5 } $13 / 9$ & 3 & 2 & 0,47 & 1,82 \\
$20 / 9$ & 20 & 15 & 0,54 & 2,23 \\
$25 / 9$ & 50 & 26 & 0,79 & 4,10 \\
$2 / 10$ & 85 & 38 & 4,27 & 5,27 \\
$10 / 10$ & 110 & - & 9,84 & - \\
& $\mathrm{C}$ & $\mathrm{D}$ & $\mathrm{C}$ & $\mathrm{D}$ \\
\cline { 2 - 5 } & 1 & 0,2 & 0,48 & 0,76 \\
$3 / 9$ & 5 & 2 & 0,71 & 0,77 \\
$10 / 9$ & 20 & 30 & 2,04 & 2,81 \\
$17 / 9$ & 31 & 55 & 3,84 & 7,02 \\
$1 / 10$ & & & & \\
\hline \hline
\end{tabular}

\section{DISCUSSION ET CONCLUSIONS}

Dans la relation hôte-parasite entre le raisin et le champignon $B$. cinerea, l'influence du parasite sur

l'hôte a été particulièrement étudiée (VERHOEFF, 1980). La plante-hôte agit également sur le comportement du parasite. Les conidies de $B$. cinerea sont présentes sur le raisin à un stade précoce de développement, au voisinage de la véraison. Mais PUCHEUPLANTE \& MERCIER (1983) ont observé que les ébauches de germination avortent rapidement sur des raisins immatures. Ce n'est qu'à la proche maturité de la baie que le champignon développe normalement des tubes germinatifs capables de pénétrer par les diverses microfissures de la pellicule.

Le raisin exerce, apparemment par chimiotropisme, un effet stimulant sur la germination des conidies. Cette action est d'autant plus nécessaire que des conidies âgées de plus de $2 \mathrm{j}$ sont dépendantes de substrats exogènes pour leur germination (CLARK \& LORBEER, 1976). La présence de substances de faible poids moléculaire dans les eaux de lavage montrent que les conidies disposent, à la surface des raisins, de nutriments azotés et carbonés favorisant leur germination. La relation existant entre la richesse des eaux de lavage et la durée d'incubation lorsque les lavages sont répétés selon une technique identique semble indiquer que ces substances sont exsudées de façon naturelle.

D'après BESSIS (1977), les fractures bordant l'auréole péristomatique constituent une voie privilégiée pour la sortie de substances. Ceci explique qu'au cours de la maturation, le rapport sucres/acides des 

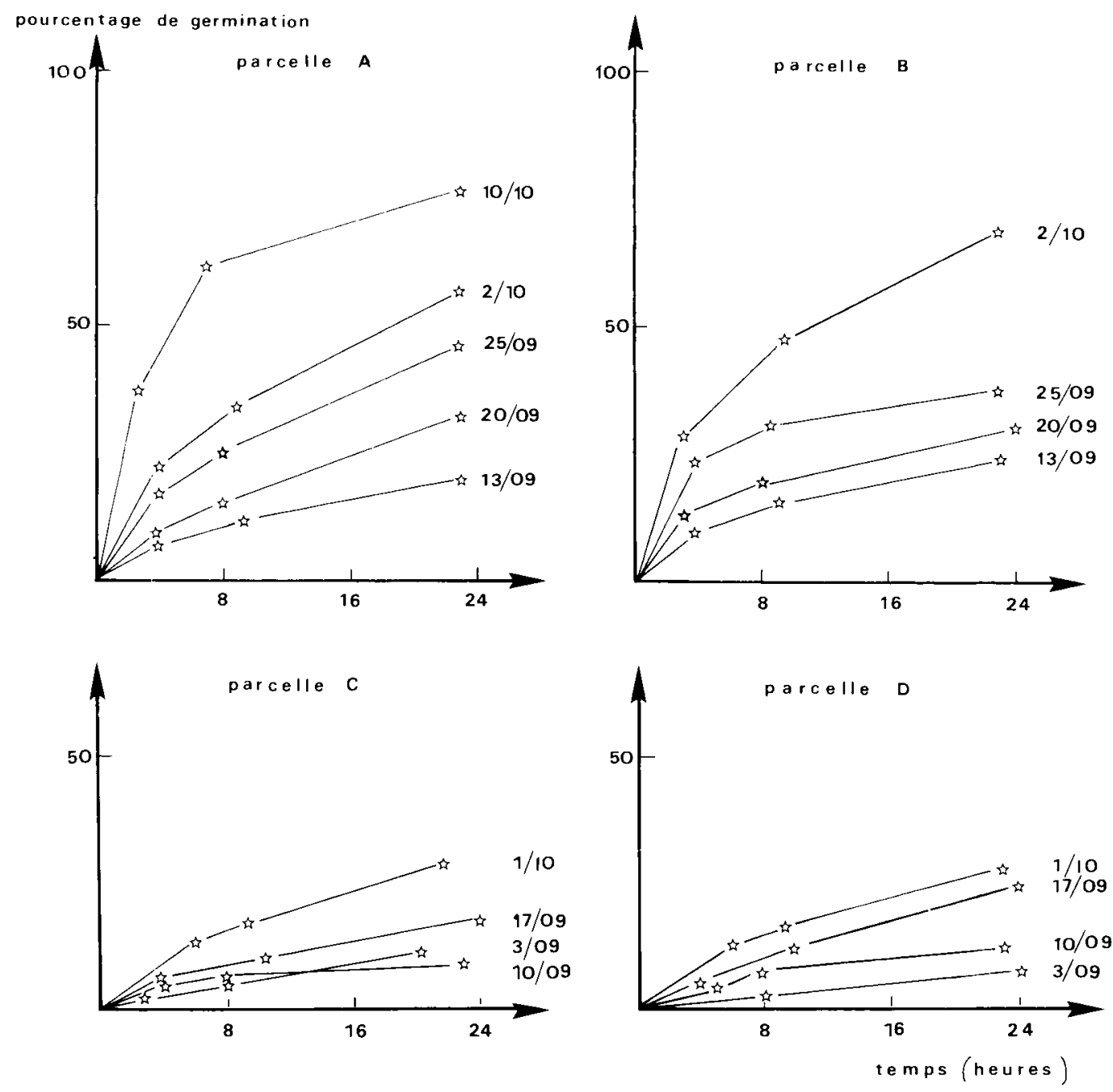

Figure 6

Influence des exsudats de raisins sur la germination des conidies de Botrytis cinerea au cours de la maturation du raisin.

exsudats évolue d'une façon similaire à celle de la constitution interne des raisins. Mais, lorsque le raisin est parvenu à maturité, la teneur en sucres simples des exsudats continue à croître fortement. De profondes modifications affectent les parois cellulaires de la pellicule au cours du processus de maturation et les substances exsudées pourraient alors provenir d'une excrétion à travers la cuticule par des voies analogues à celles empruntées par les cires. La germination des conidies est alors stimulée et le développement mycélien devient important. L'élongation rapide du tube germinatif permet ainsi à $B$. cinerea de pénétrer par les microfissures de la pellicule. Ces résultats confirment les observations réalisées par KAMOEN (1976) chez le bégonia. Cet auteur a établi une relation entre la concentration en sucres très élevée de la plante à certaines
Effect of grape berry exudates on the germination of conidia of Botrytis cinerea during grape maturation.

époques (juin et octobre) et sa prédisposition pour les affections causées par $B$. cinerea. L'effet activateur du pollen de la vigne sur la germination des conidies (LEHOCZKY, 1975) doit également résulter de l'exsudation possible de sucres simples dans la zone stigmatique.

Reçu le 30 avril 1985. Accepté le 20 août 1985.

\section{REMERCIEMENTS}

Nous exprimons nos remerciements à $M$. lt professeur G. SEGUIN pour ses remarques sur le manuscrit et à l'ensemble de l'équipe de Pédologie viticole de l'Institut d'Oenologie pour leur aide efficace dans la réalisation de ces expériences. 


\section{RÉFÉRENCES BIBLIOGRAPHIQUES}

Bergmeyer H. U., 1974. Methods of enzymatic analysis. Verlag Chemie Weinheim ed., Academic Press, New York.

Bessis R., 1977. Caractères et développement des exsudats au cours de la maturation du raisin. In "Le raisin de table et le froid". C. R. Symp. IIF et OIV; Science et Technique du Froid, Paris. Brown W., 1922. Studies in the physiology of parasitism. VIII. On the exosmosis of nutrient substances from the host tissue into the infection drop. Ann. Bot., 36, 101-119.

Clark C. A., Lorbeer J. W., 1976. The development of Botrytis squamosa and $B$. cinerea on onion leaves as affected by exogenous nutrients and epiphytic bacteria. In C. A. Dickinson \& T. F. Preece : "Microbiology of aerial plant surfaces ». Academic Press, New York.

Deverall B. J., Wood R. K. S., 1961. Infection of bean plants (Vicia faba L.) with Botrytis cinerea and B. fabae. Ann. Appl. Biol., 49, 461-472.

Kamoen O., 1976. Pathogenesis of Botrytis cinerea studied on tuberous Begonia. Verhandelingen Rijksstation voor Plantenziekten, Publicatie $\mathrm{N}^{\circ} 23$.
Kosuge T., Hewitt W. B., 1964. Exudates of grape berries and their effect on germination of conidia of Botrytis cinerea. Phytopathology, 54, 167-172.

Lehoczky J., 1975. Effect of grapevine pollen on the germination of conidia of Botrytis cinerea. Acta Phytopathol. Acad. Sci. Hung., 10, 287-293.

Nelson K. E., 1951. Effect of humidity on infection of table grapes by Botrytis cinerea Pers. Phytopathology, 41, 859-864.

Pucheu-Plante B., Mercier M., 1983. Etude ultrastructurale de l'interrelation hôte-parasite entre le raisin et le champignon Botrytis cinerea : exemple de la pourriture noble en Sauternais. Can. J. Bot., 61 (6), 1785-1797.

Verhoeff K., 1980. The infection process and host-pathogen interactions. In J. R. Coley-Smith, K. Verhoeff \& W. R. Jarvis : «The Biology of Botrytis species ". Academic Press, New York.

Warburg O., Christian W., 1941. Isolierung und Kristallisation des Garüngsfermentes. Biochem. Z., 310, 384-421. 